\title{
The Risk
}

\author{
David G. McLone, Editor-in-Chief
}

As a pediatric neurosurgeon, I am frequently asked about the safety or risk of participation in various activities by children. Our society seems intent on developing recreational devices that thrill the child, but also carry significant morbidity for this young vulnerable population. This, coupled with the lack of a common-sense approach to athletics, places children at risk of life-long disability. Almost all of the mortality and much of the severe morbidity are the result of trauma to the child's central nervous system. Add automobiles, falls, firearms, swimming pools and fire to this, and over 13,000 children die each year [1]. Unfortunately, the neurosurgical treatment of the survivors has made little progress in recent years. Obviously, the area where significant progress can be made is in the prevention of unintentional trauma.

Motor vehicle injuries remain the leading cause of traumatic death for children. While there has been a major reduction in fatality rates in the last 30 years, protection of the child occupant and child pedestrian remains a problem. The proper restraint for a child passenger is often poorly understood. The use of car seats is very effective in decreasing the risk for young children. Booster seats are necessary after the child reaches 4 years or $40 \mathrm{lb}$ until the child is large enough for the shoulder harness and lap belt. Belt use by teenagers, despite the risk, remains low.

In spite of the rate reduction of pedestrian injuries, a great deal more is needed; pedestrian-motor vehicle collisions remain a major cause of brain injury and life-long disability. Important risk factors have been identified: male gender, age 5-9 years, poverty, traffic volume, speed, absence of playgrounds. The knowledge of the risk factors should enable us to change the environment for the benefit of the child pedestrian.

An article by the American Academy of Pediatrics Committee on Injury and Poison Prevention entitled 'Children in Pickup Trucks' left me stunned. That an adult could miss the obvious hazards of placing a child in the cargo area is amazing. The results are intuitive. Death is 8 times more likely in a crash if you are in the cargo area than if restrained in the cab [2]. The amount and severity of injuries follow the same pattern.

In 1998, there were over 32 million registered pickup trucks. Seventy-three percent were for personal transportation. In 1997, 161 people died riding in the cargo area; half were children, 7 were less than 5 years old. Fewer than half of the states restrict transport of passengers in the cargo area, and only 1 state fully prohibits transport in the cargo area. Infants should not ride in the front seat of pickup trucks equipped with air bags. Many rear seats of pickup trucks are inadequate to accommodate an infant seat.

Snowmobiles, jet skies, motorcycles and 3- to 4-wheel all-terrain vehicles add to the risks of childhood. Our affluent society enables parents to afford these machines, and they are considered a family sport. The annual expenditure on snowmobiling alone is over $\$ 9$ billion. Between 1990 and 1998, 75 children died on snowmobiles. Head

\begin{tabular}{ll}
\hline KARGER & ( ) 2001 S. Karger AG, Basel \\
Fax +4161306 1234 & 1016-2291/01/0344-0169\$17.50/0 \\
$\begin{array}{l}\text { E-Mail karger@karger.ch } \\
\text { www.karger.com }\end{array}$ & $\begin{array}{l}\text { Accessible online at: } \\
\text { www.karger.com/journals/pne }\end{array}$
\end{tabular}


and neck injuries were the leading cause of death. Striking a stationary object was the commonest mechanism in a fatal crash. Children as young as 8 years can operate a snowmobile in some states, and few states have age restrictions and helmet laws [3].

Approximately 1,500 children die each year from drowning. Half of the children that reach the hospital will die. Medical care has had little impact on outcome. Only self-inflicted gunshot wounds has a higher mortality. Children breathing spontaneously when they reach the hospital are likely to survive, children requiring cardiopulmonary resuscitation will almost certainly die or survive with severe neurological damage. This is another area where primary prevention is the answer. Reduction in risk can be achieved by pool fencing, swimming lessons, parental supervision, life jackets, boating licenses and instruction. Simple things, such as children with seizure disorders should not use bathtubs but rather showers, can prevent mortality for these children.

Annually approximately 1,000 children younger than 15 years of age die in fires. This is the fourth commonest cause of unintentional injury related to death. Home fires caused $90 \%$ of the deaths in children. Smoke inhalation rather than direct burns is the principle cause of death [4].

Children and adolescents younger than 18 years account for $52 \%$ of those arrested for arson. Preteens may start fires, but usually older juveniles who set fires have serious psychological problems.

Several strategies might mitigate fires. These include adult supervision, smoke alarms, escape plans (practiced), sprinkler systems and avoiding elevators. If clothing catches fire, the child needs to know to stop, drop and roll.

Helmets have great protective value for bicycle riders. This has been known for some time, yet the use of helmets remains low among children. A survey in 1991 reported that $26 \%$ owned a helmet and only $15 \%$ wore a helmet 'most or all of the time'. It is common to see a young child on the back of a bike helmeted, while the parent is not wearing a helmet. The message to the child is clear. If 70\% of school children would wear a helmet, more lives would be saved, injuries prevented and long-term disability reduced more than by any other injury control intervention [5]. A national campaign to promote helmet use is sorely needed.

Skate boards, roller blades and now scooters give children mobility at speeds that approach the loss of control. Thousands of emergency room visits, fractures, head injuries and occasional deaths are attributed to these toys.
These and yet to be developed wheeled devices are very popular and are unlikely to go away. A common-sense approach is needed to reduce the morbidity they inflict on children. Helmets, pads and splints are important safeguards, and parents need to restrict the areas where children use the devices, obviously away from automobile traffic.

Recent surveys demonstrated that $33-40 \%$ of US households have a gun, and 1 in 5 gun owners report keeping at least 1 gun loaded and unlocked. In 1997, 142 children under 14 years died from unintentional shootings [6]. Legislators in 17 states have passed laws that make a gun owner criminally liable if the gun is not stored safely and a child uses it to injure himself or others; in Florida it is a felony. In Florida alone, there was a $51 \%$ decline in unintentional firearm deaths in children attributed to this legislation.

Available data indicate that an estimated 83,400 trampoline-related injuries occurred in 1996. Most were sustained on home trampolines. The American Academy of Pediatrics' recommendation is that trampolines should never be used in the home environment, in routine physical education classes or outdoor playgrounds [7].

Collision sports like American football, soccer and ice hockey present wonderful opportunities for recreation and social development, but not without some risk. Again, common sense by the adults responsible for these programs can significantly reduce the rate and severity of injuries.

In the US, 3 million youths are registered for high school soccer. About 150,000 injuries were recorded for years 1992 through 1994. Nearly half were in children younger than 15 years. Contact between players accounts for between 30 and $70 \%$ of injuries [8]. Fatalities in soccer are almost exclusively related to traumatic contact with goal posts. Head and facial injuries account for $5-22 \%$ of soccer injuries.

The cognitive consequences of 'heading' the ball has raised some concerns. A study in Norway of matched controls and adult soccer players showed mild to severe deficits in attention, concentration and memory in $81 \%$ of the players. The frequency of heading also correlated with the severity of the cognitive loss. For the present, adults that supervise participants should minimize heading until more data are available. Eye injuries and orofacial trauma are common, and can be reduced with the use of protective eyewear and mouth guards. Above all, violent and aggressive behavior should be strongly discouraged.

This opens the whole question of the concussed child or adolescent athlete. It has been known for some time 
that repeated concussions lead to major disability in boxing, and this is finally being recognized in American football, even at the professional level. It is difficult, if not impossible, to prevent concussions in American football. At what frequency this is tolerable and how long a young athlete should be restricted from competition remains unclear. Again, common sense would indicate that frequent concussions in close proximity to each other are a concern. A reasonable time away from a collision sport following a concussion obviously makes good sense. It is often difficult to convince the young athlete and the parents of the importance of this time off.

Ice hockey is played by 200,000 children in the US. An increase in serious head and neck injuries related to body checking has alarmed the hockey community. In the 1960s, due to facial injuries, mandatory use of helmets with a facemask was indicated. It was remarkably successful in reducing facial injuries. However, there was a concomitant increase in neck and spinal injuries. The mask seemed to create a false sense of protection from injury. A similar observation was made in American football. A Canadian study in 1984 noted 42 spine injuries with the mean age being 17 years and of the 42,28 had spinal cord injuries. A recent US study showed that body checking accounts for $86 \%$ of all injuries. Disparities in size and strength can further increase the risk for serious injury. American Academy of Pediatrics recommendations include: no body checking for children 15 years and younger, good sportsmanship reduces injuries, and an education program for players, coaches and parents is needed [9].

The most devastating injuries to children come from the environment that the child lives in. While we cannot totally protect children, we can, with common sense, lessen the risk. This begins with knowing what the risks are and then minimizing and removing them. More research is also needed to further elucidate risks and develop methods to control them.

\section{References}

1 Rivara FP: Pediatric injury control in 1999: Where do we go from here? Pediatrics 1999; 103:883-888.

2 Committee on Injury and Poison Prevention: Children in pickup trucks. Pediatrics 2000; 106:857-859.

3 Rice MR, Alvanos L, Kenney B: Snowmobile injuries and deaths in children: A review of national injury data and state legislation. Pediatrics 2000;105:615-619.
4 American Academy of Pediatrics Committee on Injury and Poison Prevention: Reducing the number of deaths and injuries from residential fires. Pediatrics 2000;105:1355-1357.

5 Bergman AB, Rivara FP: Why do child cyclists in the United States remain unhelmeted. Pediatrics 1999;104:107-109.

6 Webster DW, Starnes M: Reexamining the association between child access prevention gun laws and unintentional shooting deaths of children. Pediatrics 2000;106:1466-1469.

7 American Academy of Pediatrics Committees of Injury and Poison Prevention and on Sports Medicine and Fitness: Trampolines at home, school and recreational centers. Pediatrics. 2000;105:657-658
8 American Academy of Pediatrics Committee on Sports Medicine and Fitness: Injuries in youth soccer: A subject review. Pediatrics 2000;105:659-661.

9 American Academy of Pediatrics Committee on Sports Medicine and Fitness: Safety in youth ice hockey: The effect of body checking. Pediatrics 2000;105:657-658. 